\title{
CORRESPONDENCE
}

\section{OPERATION FOR CONGENITAL CATARACT}

To the Editorial Committee of the British Journal of Ophthalmology,

SIRS-I have today seen a patient who makes one feel more cheerful about the results of operation for congenital cataract.

Both eyes were operated on at about the age of 15 , at Moorfields, by Mr. Adams. The patient is now aged 90 and with glasses 60 years old can see $6 / 9$ with the right eye and $6 / 6$ with the left, and can read the smallest print with comfort. He has sought advice only because one of these venerable spectacles has been broken.

Yours faithfully,

R. A. D. Crawford.

10, New DOVER Road,

CANTERBURY.

June 29, 1956.

\section{BOOK REVIEW}

Surgery of the Eye: Diseases. By Alston Callahan. 1956. Pp. 447, 263 figs, bibl. Thomas, Springfield, Ill. (£9).

Callahan's volume on the surgery of ocular injuries is now well recognized as the best available treatise on this subject; its companion volume on the surgery of ocular diseases is equally good. The first chapter deals fully and interestingly with anaesthesia, local and regional analgesia, akinesia and the use of curare, and general anaesthesia as applied to ophthalmic surgery. The next five chapters deal with the surgery of the lids; this section is particularly well done, the innumerable techniques available having been cut down te reasonable numbers. The next chapter deals with congenital anomalies, principally congenital cataract and goniotomy for infantile glaucoma. In the chapter on corneal diseases, surprise may be felt that the author is able to dispose of keratoplasty in six pages. The surgery of cataract, on the other hand, absorbs six chapters-pre-operative treatment, surgical techniques, operative, early and late post-operative complications, and capsulotomy and kindred operations. The surgery of glaucoma is fully covered in seven chapters; there follow sections on retinal detachment, the ocular muscles, removal of the eye and the use of implants, and surgery of the orbit.

The book ends with appendices on advancements in surgical techniques for dealing with injuries of the eye and its adnexa which have appeared since the companion volume was written.

The writing is clear and the operative techniques, laid out in numbered steps, are easy to follow, a task rendered much more simple by the abundance of admirably clear diagrammatic illustrations. No attempt is made to trace or analyse the literature, and descriptions of a multiplicity of techniques are not allowed to fog the issue. We have here the author's own practice derived from his own experience; and his choice of techniques has been sound. He has had help from many of the best surgical opinions in America and beyond (Atkinson on anaesthesia, Berke, Hughes, and Reeh on plastic surgery, Cordes on congenital cataract, Franceschetti on corneal surgery, Schepens on retinal detachment, Burian and Fink on muscle surgery); the result is a volume of great value and a welcome addition to our literature.

\section{OBITUARY}

The whole ophthalmological profession in Great Britain is very sad to learn of the death of Professor G. P. Sourdille, of Nantes, on August 21st, 1956. An obituary notice will appear in an early issue of this Journal. 